\title{
Comparison of Purification Efficiencies of Different Affinity Separation Techniques
}

\author{
Matthias Koetke ${ }^{1}$, Henning Rosenfeld ${ }^{*}, 1$, Stephanie Peper ${ }^{2}$ and Bernd Niemeyer ${ }^{1,2}$ \\ ${ }^{1}$ Institute for Coastal Research/Marine Bioanalytic Chemistry, GKSS Research Centre, Max-Planck-Strasse, D-21502 \\ Geesthacht, Germany \\ ${ }^{2}$ Institute of Thermodynamics, Helmut-Schmidt-University/University of Federal Armed Forces Hamburg, \\ Holstenhofweg 85, D-22043 Hamburg, Germany
}

\begin{abstract}
An affinity separation method for the isolation of recombinantly produced benzoylformiate decarboxylase (BFD) is presented based on the interaction of the enzyme to its cofactor. Enzyme/cofactor interactions are well suited for affinity purification processes with regard to its high affinity and selectivity. Problems can be induced due to harsh desorption conditions that probably diminish the activity of the purified enzyme. The implementation of boronic acids to immobilize the cofactor introduces a gentle release by a simple $\mathrm{pH}$ shift from 8.5 to 6 . The disadvantages of $\mathrm{m}$ aminophenyl boronic acids are the high nonspecific adsorption induced by the introduction of a positive charge and a hydrophobic phenyl ring. It was shown that the disadvantages prevail and boronic acid resins are not suitable for protein purification from complex matrices. In contrast to the affinity separation method, where the cofactor was directly immobilized onto the support, a better separation performance could be achieved, which is reflected by a purification factor of 4 .
\end{abstract}

Keywords: Affinity separation, boronic acid, BFD, benzoylformate decarboxylase, thiamine pyrophosphate.

\section{INTRODUCTION}

Benzoylformate decarboxylase (BFD, EC 4.1.1.7) is a thiamine pyrophosphate (TPP) constrained enzyme of the mandelate pathway from Pseudomonas putida, where it catalyzes the non-oxidative decarboxylation from benzoylformate to benzaldehyde and $\mathrm{CO}_{2}$. The enzyme is composed of four identical subunits each of $\sim 55 \mathrm{kDa}$ size (Fig. 1) $[1,2]$.

Besides its decarboxylating activity the enzyme may act also as a carboligase, catalyzing the reaction of an $\alpha$-keto acid and an aldehyde, which results in chiral 2-hydroxy ketones (HPP) with a high enantiomeric excess. It is not fully understood, whether the carboligase activity is of physiological importance or just a not required function of the enzyme in Pseudomonas putida [3]. Wilcocks et al. described the carboligase activity of BFD for the first time. They observed formation of (S)-2-hydroxy-1phenylpropanone and byproducts in the presence of benzoylformate and acetaldehyde $[4,5]$. Early studies of the substrate variability of BFD showed that the aromatic ring is a prerequisite for enzymatic activity [6]. Only low decarboxylase activity was found with aliphatic $\alpha$-keto acids. Less discriminating is the enzyme against changes or presence of the carboxyl group. The corresponding aldehydes of $\alpha$-keto acids get also converted. Iding et al. applied BFD for the synthesis of chiral 2-hydroxy ketones using benzaldehyde or meta-substituted benzaldehydes as

*Address correspondence to this author at the Institute for Coastal Research/Marine Bioanalytic Chemistry, GKSS Research Centre, MaxPlanck-Strasse, D-21502 Geesthacht, Germany; Tel: +49(0)4152/87-2831; Fax: 49(0)4152/87-1875; E-mail: henning.rosenfeld@gkss.de substrates [7]. Chiral 2-hydroxy ketones are important structural subunits in many biologically active products and are also important precursors for chemical synthesis [7,8]. This makes BFD a promising tool for stereo selective C-Cbond formation instead of the classical benzoin condensation $[7,9]$.

The isolation of proteins from recombinant organisms like E. coli can be accomplished via introducing histidine tags and subsequent nickel nitrilotriacetic acid affinity separation. However in some cases cross reactivities occur with other histidine rich proteins that make further protein purification steps necessary. Therefore an affinity separation step using the enzyme/coenzyme interaction is preferable, because this interaction has both: A high selectivity and a high affinity. The challenge in the process is to create a mild and function preserving desorption step for the enzyme from immobilized coenzyme. The idea for using boronic acids with immobilized coenzyme is to exploit the advantages of the interaction with creating simultaneously easy desorption conditions caused by a simple $\mathrm{pH}$ shift.

The interaction of boronic acids with vicinal alcohols has been known for several decades [10]. In aqueous solution under basic conditions, the boron atom rearranges from trigonal coplanar form to a tetrahedral boronate anion, where it is possible to bind cis-diols e.g. sugars and form cyclic esters [11]. Fig. (2) shows a schematic mechanism of diolbinding to boronic acids.

In reality the whole process is much more complex as stated from James et al. [12]. According to Bosch et al. boronic acids are also able to form covalent bonds with phosphates resulting in a binary stable complex [13]. The most common boronic acid separation material in affinity 

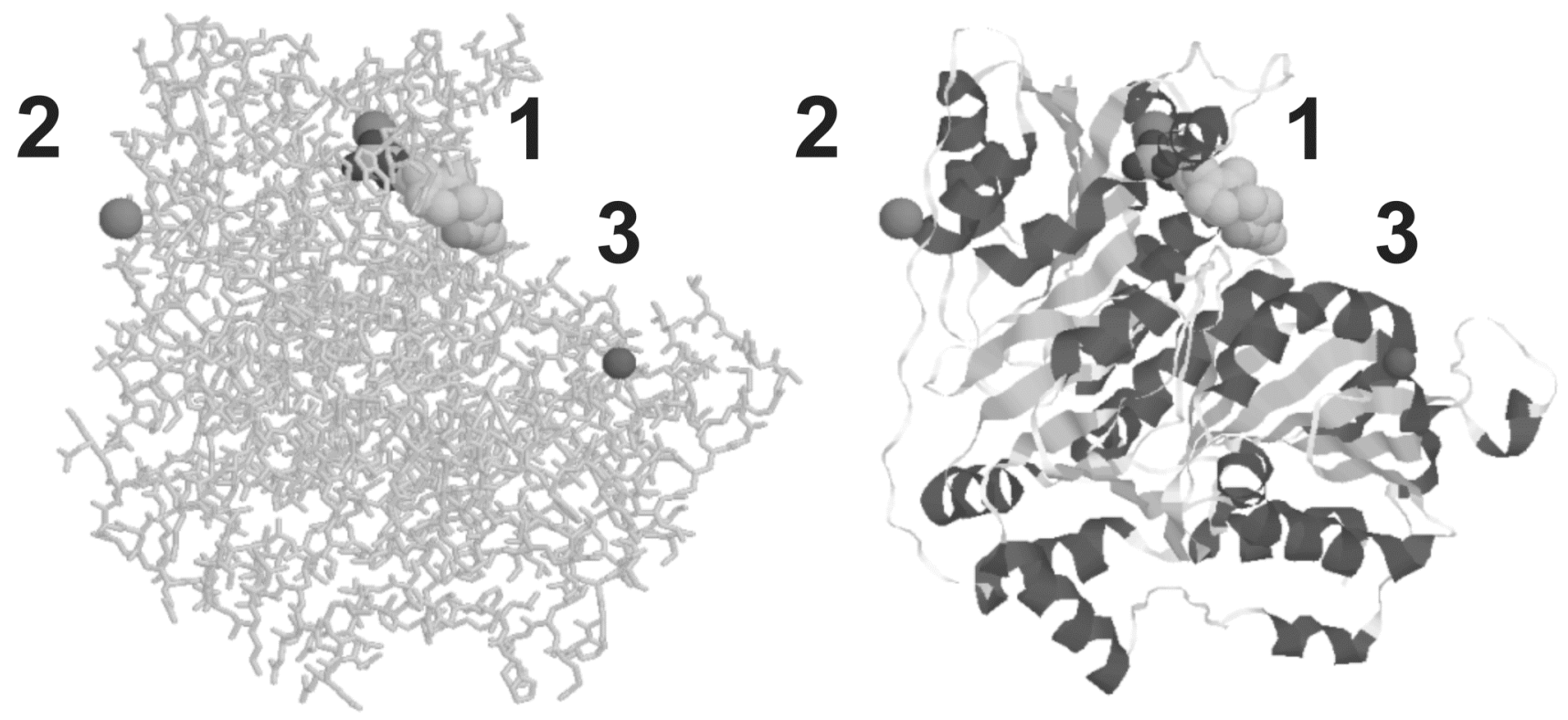

Fig. (1). $55 \mathrm{kDa}$ subunit of BFD in complex with TPP (1) and divalent cations calcium (2) and manganese (3); left: stick model, right: ribbon model [2; pdb file: $1 \mathrm{bfd}]$.

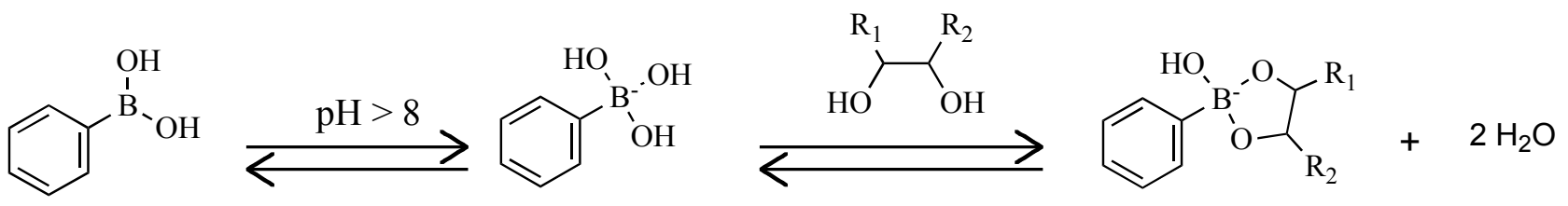

Fig. (2). Interaction between boronic acid and a cis-diol in aqueous solution.

separation is immobilized m-aminophenylboronic acid (ABA), which was also used here to immobilize TPP as a secondary ligand through the formation of a linkage to its phosphate group. This immobilization has another advantage, because the molecule orientation results in a good accessibility for the BFD. Maestas et al. introduced this concept of affinity separation as "ligand-mediated" chromatography [14].

To desorb the bound target enzymes together with its cofactor a $\mathrm{pH}$-shift to acidic conditions is sufficient to cleave the linkage between the ABA and the second affinity ligand. Sometimes a competitive displacement is also feasible [15].

This paper evaluates critically the performance of ABA affinity adsorbents, including a comparison of an affinity separation method, where TPP was immobilized directly via its amine group to the matrix without using the boronic acids. The strength and weaknesses of these methods were evaluated.

\section{MATERIAL AND METHODS}

E. coli cells were supplied from the working group of Prof. Liese from the Institute of Technical Biocatalysis, Hamburg University of Technology (Hamburg, Germany). For the preparation of the adsorbents m-aminophenylboronic acid was purchased from Sigma Aldrich (Munich, Germany) and the support Toyopearl AF-Tresyl-650 was obtained from Tosoh Bioscience (Stuttgart, Germany).

Thiamine hydrochloride, thiamine pyrophosphate, manganese chloride, 2-[4-(2-hydroxyethyl)piperazine] ethansulfonicacid (HEPES) and acetonitrile were also from Sigma-Aldrich. Hydrochloric acid (37 \%), $\mathrm{NaCl}, \mathrm{Na}_{2} \mathrm{HPO}_{4}$, $\mathrm{NH}_{4} \mathrm{HCO}_{3}$ originates from Merck (Darmstadt, Germany). All chemicals were from the highest purity available otherwise stated.

\subsection{Cell Disruption of Recombinant $E$. coli}

Cells were disrupted by sonification with a Sonifier 450 equipped with a cup horn from Branson (Dietzenbach, Germany). $10 \mathrm{~g}$ of frozen E. coli cells were allowed to thaw and mixed with pulping buffer $\left(2 \mathrm{M} \mathrm{K}_{2} \mathrm{HPO}_{4}, 2 \mathrm{mM} \mathrm{MgCl}\right.$, $\mathrm{pH}$ 7.5). The cells were divided in $5 \mathrm{~mL}$ aliquots and disrupted two times with $1 \mathrm{~min}$ impulse (duty cycle $70 \%$ ) in the sonification disrupter at maximal power. The aliquots were recombined and centrifuged at $5000 \mathrm{~g}$. The supernatant was collected to continue processing. Determination of protein concentration was carried out at $280 \mathrm{~nm}$ against running buffer and with Bradford's method [16].

\subsection{Preparation of the Adsorbents}

ABA was immobilized onto Toyopearl AF-650 tresyl support by combining $0.5 \mathrm{~g}$ of the tresylated support with $4 \mathrm{~mL}$ of a $21.3 \mu \mathrm{M}$ ABA solution. The reaction medium is a PBS buffer $\left(0.5 \mathrm{M} \mathrm{Na}_{2} \mathrm{HPO}_{4}, 0.5 \mathrm{M} \mathrm{NaCl}, \mathrm{pH} 8\right)$. The reaction took $4 \mathrm{~h}$ with gently shaking. The ABA content in the supernatant was measured for determination of the immobilization yield. Quantification occurred by measuring the extinction at $296 \mathrm{~nm}$ with a Spekol Uv/Vis photometer from Analytik Jena (Jena, Germany). Blocking of residual tresyl groups was done with $0.5 \mathrm{M}$ tris buffer also at $\mathrm{pH} 8$. 
For the immobilization of TPP onto the Toyopearl support, the same buffer was used which is beneficial for the reaction with tresyl groups. TPP was added in excess to the support using the same procedure.

\subsection{Binding Studies with Thiamine Pyrophosphate (TPP) and Thiamine Hydrochloride (THC)}

Binding of TPP to the boronic acid support is considered to be a crucial step for the separation success and was therefore investigated in more detail. The amounts of immobilized molecules were determined indirectly by supernatant analysis. $0.5 \mathrm{~g}$ dry resin $\mathrm{ABA}$ adsorbent was filled in Econo glass columns. $10 \mathrm{~mL}$ of the TPP or THC solution were applied to the column. The final concentrations of TPP ranged from 0.02 to $0.3 \mathrm{M}$, while with THC a $0.2 \mathrm{M}$ solution was prepared. Because of the acidic properties of THC and TPP the $\mathrm{pH}$ of the solution had to be adjusted again to $\mathrm{pH} 8.5$ with $\mathrm{NaOH}$ after dissolving, which is required for the binding to $\mathrm{ABA}$. The columns were locked and put in a heating cupboard at $40^{\circ} \mathrm{C}$ for $16 \mathrm{~h}$. After washing the excess of THC or TPP from the column desorption occurred with change of the $\mathrm{pH}$ to 6 . The eluted volume was collected in appropriate volumetric flask. The quantification of THC and TPP was done by means of UV/Vis spectroscopy at $296 \mathrm{~nm}$ in $1 \mathrm{~cm}$ cuvette against phosphate buffer [17]. A linear calibration of TPP was taken in phosphate buffer from $4.3 \mu \mathrm{M}$ to $56.7 \mu \mathrm{M}$. High regression coefficients (typically: $\mathrm{R}>0.99$ ) were achieved.

\subsection{Isolation of BFD from the Crude $E$. coli Cell Broth by Means of Affinity Separation}

$12.3 \mathrm{~mL}$ ABA adsorbent with an ABA content of $25 \mu \mathrm{mol} / \mathrm{g}$ was equilibrated and saturated with TPP $(0.2 \mathrm{M}$ in running buffer) in an Econo glass column. The immobilization occurred overnight in a heating cupboard at $40{ }^{\circ} \mathrm{C} .1 \mathrm{~mL}$ of cell broth was diluted with $1 \mathrm{~mL}$ running buffer (0.01 M HEPES, $0.15 \mathrm{M} \mathrm{NaCl}, 2 \mathrm{mM} \mathrm{MgCl} 2, \mathrm{pH} \mathrm{8.5)}$ applied to the column. After washing with three column volumes, desorption was accomplished by changing to an acidic phosphate buffer $\left(10 \mathrm{mM} \mathrm{KK_{2 }} \mathrm{PO}_{4}, 0.15 \mathrm{M} \mathrm{NaCl}\right.$, $2 \mathrm{mM} \mathrm{MgCl} 2, \mathrm{pH} \mathrm{6}$ ). The flow was set to $1.8 \mathrm{~mL} / \mathrm{min}$ and detection occurred at $254 \mathrm{~nm}$.

The isolation of BFD without ABA was also carried out in a batch. The crude cell broth was applied to the Toyopearl-TPP support in $0.01 \mathrm{M}$ PBS $(0.15 \mathrm{M} \mathrm{NaCl}$, $\mathrm{pH}$ 7.4) and washed three times. Desorption was accomplished by the use of competitive displacement by incubation in a $0.2 \mathrm{M}$ TPP solution. Afterwards ultrafiltration removes excessive TPP and concentrates the enzyme solution.

The collected desorption fractions of the column and batch experiments were collected and checked for purity, enzyme activity and protein content.

\subsection{Determination of the Enzyme Activity}

The activity of BFD was determined by using the enzyme test according to Iding et al. [7]. It based on measuring the decrease of substrate benzoylformate, which was monitored for $90 \mathrm{~s}$ at $340 \mathrm{~nm} .50 \mu 1$ of a BFD solution got filled up with $950 \mu 1$ substrate buffer (pH 6) comprising $0.15 \mathrm{M} \mathrm{KH}_{2} \mathrm{PO}_{4}$, $2 \mathrm{mM} \mathrm{MgCl}, 0.1 \mathrm{mM}$ TPP and the $10 \mathrm{mM}$ of the substrate benzoylformate. The reaction happens at $30{ }^{\circ} \mathrm{C}$. Enzyme activity was calculated using the following equation.

$$
U=\Delta A_{\lambda} * \frac{V_{\text {total }}}{V_{\text {sample }} * d * \varepsilon}
$$

$U: \quad$ Enzyme activity in $\mathrm{U} / \mathrm{mL}$

$\Delta A_{\lambda}$ : Change in absorption per minute

$V_{\text {total }}$ : Total volume in the cuvette in $\mathrm{mL}$

$V_{\text {sample: }}$ Sample volume in $\mathrm{mL}$

$d$ : Thickness of the cuvette in $\mathrm{cm}(1 \mathrm{~cm})$

\&: $\quad$ Molar absorption coefficient $\mathrm{L}^{*} \mathrm{mmol}^{-1} * \mathrm{~cm}^{-1}$ $\left(0.032 \mathrm{~L}^{*} \mathrm{mmol}^{-1} * \mathrm{~cm}^{-1}\right.$ for benzoylformate)

The assay based on the decarboxylation of benzoylformate resulting in the formation of benzaldehyde; having a different absorption maximum. A qualitative verification of the activity can simply be achieved by smelling. The reaction product benzaldhyde has a typical marzipan like odor.

\subsection{Two-Dimensional Gel Electrophoresis (2-DE) and Identification of BFD with MALDI-TOF-MS}

The entire equipment and buffers used for the 2-DE was provided from BioRad (Munich, Germany). Ultrafiltration with Vivaspin ultrafiltration tubes $(10 \mathrm{kDa})$ from Sarstedt (Nümbrecht, Germany) was used prior to gel electrophoresis to desalt and concentrate the samples. The uptake of the proteins into the IPG strips took place by passive rehydration overnight. For the isoelectric focussing IPG strips were used with a linear $\mathrm{pH}$ gradient ranging from 3 to 10 and happened with rising voltage gradients in a Protean IEF cell. The separation based on the molecular weight in the gel was carried out with precast $8-16 \%$ polyacrylamide gels. Equilibration of the IPG strips was carried out in two buffers applied successively (both buffers contain $0.37 \mathrm{M}$ Tris $\mathrm{HCl}$, $6 \mathrm{M} \mathrm{Urea,} 2 \%(\mathrm{w} / \mathrm{v})$ SDS, and $30 \%(\mathrm{v} / \mathrm{v})$ glycerol; the first is spiked additionally with DTT and the second with iodoacetamide (Sigma Aldrich, Germany)). Protein staining was conducted with Coomassie Brilliant Blue.

After 2-DE spots of interest were cut out and destained with $200 \mu \mathrm{L}$ of a $40 \%$ acetonitrile in $0.2 \mathrm{M}$ ammonium bicarbonate solution. Afterwards the gel piece was dried in a vacuum centrifuge for $30 \mathrm{~min}$. The dry gel piece was soaked with $20 \mu \mathrm{L}$ trypsin solution $(20 \mu \mathrm{g} / \mathrm{mL})$ dissolved in an appropriate reaction buffer $(50 \mu \mathrm{L}$ of $40 \mathrm{mM}$ ammonium bicarbonate containing $9 \%$ acetonitrile) was added and digestion proceeded overnight at $37^{\circ} \mathrm{C}$. The resulting peptide solution can be concentrated in a vacuum centrifuge and picked up with $10 \mu \mathrm{L}$ acetonitrile/water $(1: 1, \mathrm{v} / \mathrm{v})$ with $0.1 \%$ trifluoroacetic acid (TFA) for MS analysis.

The matrix for the peptides was a 4-hydroxy- $\alpha$ cyanocinnamic acid (HCCA) solution, which was prepared by dissolving it in an ethanol:acetone mixture $(2: 1, \mathrm{v} / \mathrm{v})$. The final concentration was set to $1 \mu \mathrm{g} / \mu \mathrm{L}$. Samples and matrix were premixed in a ratio of $1: 1$ and subsequently $1.5 \mu \mathrm{L}$ of the mixture were applied to an $800 \mu \mathrm{m}$ Anchor Chip (Bruker, Germany). Crystallization occurred at room temperature. MALDI-TOF spectra were acquired using the Bruker Ultraflex II TOF/TOF mass spectrometer (Bremen, 


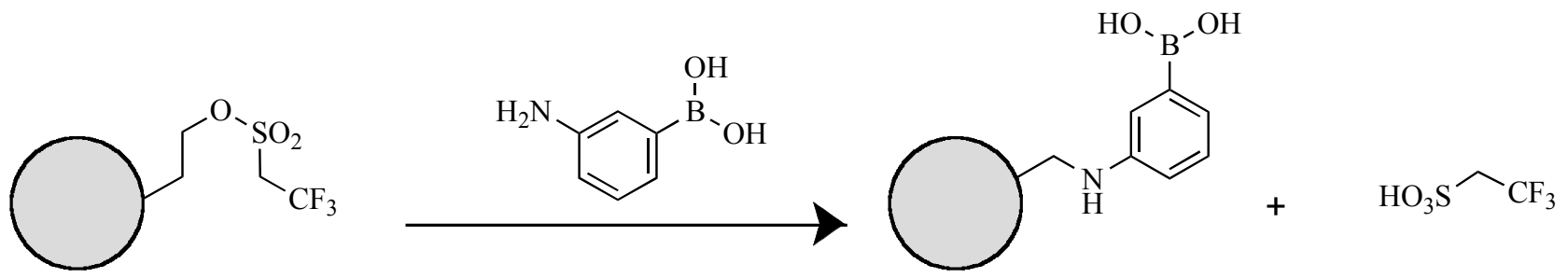

Fig. (3). Immobilization of ABA to a tresylated polymeric support (conditions: phosphate buffer (pH 8 ), 4 h, $25^{\circ} \mathrm{C}$ ).

Germany). Labelled TOF spectra were further processed in the BioTools 3.0 software package using the MASCOT MS search algorithm.

\section{RESULTS AND DISCUSSION}

\subsection{Immobilization of ABA}

The preactivated Toyopearl AF-Tresyl-650M matrix contains a hydrophilic and non-charged surface to reduce nonspecific adsorption, which is beneficial for the separation of proteins. Further the support shows a good chemical and mechanical stability in the operating $\mathrm{pH}$ range $[18,19]$.

The preparation of the adsorbent requires two immobilization steps before applying the crude cell broth. The first step comprehends the attachment of the ABA to the support and the second step is the attachment of TPP to the ABA groups. The reaction with the tresyl groups occurs with primary amines and is illustrated in Fig. (3).

The density of the active groups on the support material is about $80 \mu \mathrm{mol} / \mathrm{g}$ in desiccate state. After immobilization the support was thoroughly covered with ABA. The amount of ABA was on average $145 \mu \mathrm{mol} / \mathrm{g}$. However investigations with previously deactivated support material revealed that $55 \mu \mathrm{mol} / \mathrm{g}$ remains solely physically adsorbed in the pores of the matrix without reacting with the tresyl groups. The true immobilized ABA amount is consequently about $90 \mu \mathrm{mol}$ per gram dry resin, which is considered to be a complete conversion of the activated support. This corresponds to $41.4 \mu \mathrm{mol} / \mathrm{g}$ wet support or $3.5 \mu \mathrm{mol} / \mathrm{m}^{2}$ surface coverage.

The ligand density has a decisive impact on the separation performance, especially in the case of ABA ligands. The introduction of a phenyl ring and a negative charge gives rise to attachment for nonspecific adsorption that is known to be the main problem when using ABA as affinity ligands $[10,11,20]$.

Since TPP has a primary amine function (see Fig. 5), it is amenable for direct immobilization to the tresylated support.

A<smiles>Cc1ncc(C[n+]2csc(CCOP(=O)(O)OP(=O)(O)O)c2C)c(N)n1</smiles>

Protocols for affinity chromatography with immobilized TPP do already exist [21, 22]. Separation processes with and without ABA can be compared to evaluate the assets and drawbacks.

\subsection{Binding Studies with Thiamine Pyrophosphate (TPP) and Thiamine Hydrochloride (THC) to ABA}

The binding of TPP to the ABA molecules is considered to be the most critical step in this separation process. At first sufficient amount of TPP has to be immobilized and second it has to be in a proper orientation for the binding of the voluminous BFD molecule. The structure of TPP is depicted in Fig. (4A). The diphosphate group is located on one side of the molecule. The formation of a covalent linkage between the phosphate ions and the ABA allows the molecule to protrude into the mobile phase.

Investigations describing the formation of covalent bonds between phosphates and boronic acids under basic conditions can be retraced in detail from Bosch et al. and Springsteen \& Wang $[13,23]$. For the determination of TPP in complex matrices a derivatization is necessary [24], but for the determination of pure TPP solutions applied in immobilization experiments a direct spectrometric method is applicable [17].

It could be shown that the amount of bound TPP increases with a higher concentration of TPP, according to the law of mass action. The optimum concentration was at $0.2 \mathrm{M}$ TPP. Studies on the effect of temperature and residence time of TPP immobilization were also performed (data not shown).

Approximately $1 \%$ of all ABAs could be tagged with a TPP molecule under the selected conditions. However the surface coverage of $1 \%$ of the small TPP molecule $(\sim 424 \mathrm{~g} / \mathrm{mol})$ (assumed to occur in a consistent distribution on the support) would be sufficient to nearly saturate the surface with the voluminous BFD protein. The highest projected area of BFD is a square with $7 \times 7 \mathrm{~nm}$ measured

B<smiles>Cc1ncc(C[n+]2csc(CCO)c2C)c(N)n1</smiles>

Fig. (4). Structure of TPP (A) and THC (B). 
with Swiss-PdbViewer 4.0 [2; pdb file: 1bfd]. The used Toyopearl support has a specific surface area of $42 \mathrm{~m}^{2} / \mathrm{g}$ that carry $0.92 \mu \mathrm{mol}$ TPP assuming $1 \%$ immobilization yield. Expecting an exhaustive binding of BFD to its cofactor $27 \mathrm{~m}^{2} / \mathrm{g}$ support can be covered corresponding to a surface coverage of $64 \%$. Similar values for the ligand density can be retraced in the literature. O'Brien et al. reported for the immobilization of TPP to sepharose 4B a ligand density $6 \mu \mathrm{mol} / \mathrm{mL}$ [25]. This is about $1.5 \mu \mathrm{mol}$ per gram dry sepharose with the assumption that $1 \mathrm{~g}$ sepharose swells to $4 \mathrm{~mL}$. In addition affinity separations with lower densities are also possible. A TPP sepharose 4B resin with $0.04 \mu \mathrm{mol} / \mathrm{mL}(0.01 \mu \mathrm{mol} / \mathrm{g})$ was prepared by Matsura et al. [21].

Publications dealing with immobilizations of other cofactors like $\mathrm{NAD}^{+}$reported about saturations of $39 \%$ of all boronic acid groups, though these cofactors with high immobilization yields contain diol groups. In the same study the cofactor pyridoxal, a molecule that did not have the required diol function was used as a second affinity ligand, where binding can only occur over single hydroxyl groups. Immobilization yields of $2 \%$ of all ABA were achieved [14].

To show that binding occurred via the phosphate group from TPP, immobilization experiments with THC (Fig. 4B) were conducted. This molecule does not bear a diphosphate group and should consequently do not bind to the $\mathrm{ABA}$ support. The experimental conditions were held constant and small amounts of THC were detectable in elution fractions, which is an indication that binding did not occur exclusively over the diphosphate group. One possible explanation is that ionic interactions can take place. TPP and THC are bearing positively charged nitrogen atoms, which interact with the negatively charged boron atoms of ABA. Nevertheless affinity chromatography is feasible. In the next step a crude $E$. coli cell broth was applied to the prepared affinity adsorbents.

\subsection{Affinity Separation with Crude Cell Broth}

The cofactor/protein interaction is usually strong enough for affinity separation processes. Dissociation constants $\left(\mathrm{K}_{\mathrm{D}}\right)$ smaller than $10^{-5} \mathrm{M}$ make the required on/off-mechanism possible and allow a washing step without significant protein loss [26]. Several TPP binding proteins from microbial organisms, higher plants and animals have already been described [27]. The $\mathrm{K}_{\mathrm{D}}$ values range between $1.1 * 10^{-6} \mathrm{M}$ and $2.8 * 10^{-8} \mathrm{M}[28-32]$.

Two different TPP containing adsorbents were used for the purification of BFD from the crude cell broth. The first covered ABA to immobilize TPP and the second one is composed of directly immobilized TPP onto the support. The separation process for the ABA comprising matrix starts with the attachment of TPP to ABA. After washing excessive TPP from the column, the crude cell broth can be applied. TPP binds selectively and with high affinity to the BFD enzyme, while residual components were removed. Decrease of the $\mathrm{pH}$ by buffer change, desorbs the bound $\mathrm{BFD} / \mathrm{TPP}$ complex and the cycle can be repeated again. BFD is stable at $\mathrm{pH} 8$. Only higher $\mathrm{pH}$ values above 10 induce a deactivation of the enzyme [7]. An exemplary chromatogram of this separation process is shown in Fig. (5). The nonbinding fraction is much higher than the binding fraction. The column load was not leveled to its capacity. The high flow through comprises excessive BFD and diverse other proteins of the crude mixture.

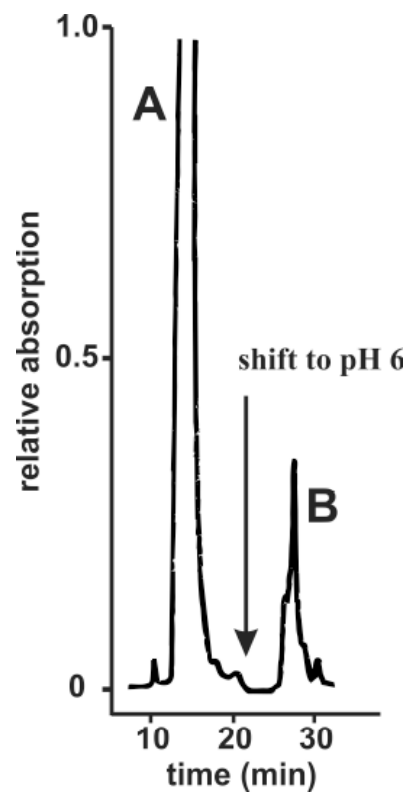

Fig. (5). Chromatogram of TPP-ABA affinity separation. A: flow through fraction; $\mathbf{B}$ : elution fraction.

The affinity separation cycle with covalently immobilized TPP was carried out in a batch experiment, because desorption occurred with $0.2 \mathrm{M}$ TPP solution to replace the bound enzyme competitively. UV/Vis detection of desorbed proteins is not possible in the presence of TPP. Competitive desorption of other thiamine depending proteins of E. coli were described by Muniyappa et al. and O'Brien et al. $[25,27]$. To retrace the performance of the prepared adsorbents, 2DE was fabricated and pictured in Fig. (6).

The gel at the top shows the high amounts of proteins present in the crude cell extract. BFD constitutes in a huge spot at $55 \mathrm{kDa}$. Identification of BFD in the gels was done by tryptic digest and MALDI MS experiments presented in Fig. (7).

The used crude cell broth has an enzyme activity of $72.4 \mathrm{U} / \mathrm{mL}$ and protein content was determined to $7.3 \mathrm{mg} / \mathrm{mL}$ with the Bradford method. This yielded in a specific volume independent enzyme activity of $10 \mathrm{U} / \mathrm{mg}$ of the crude cell broth. The cell lysate was applied to ABA-TPP adsorbents and the separation success is visualized with the gel on the left hand side in Fig. (8) and calculated by means of a purification factor that is the recovered enzyme activity divided by the total protein content of the isolated fraction.

The gel contains many other proteins in addition to the BFD spot, indicating a low purification factor. In fact the enzyme activity was calculated to $6.4 \mathrm{U} / \mathrm{mg}$ which is lower than in the crude cell broth. This is caused by several ionic and hydrophobic interactions of the negative charge of the boron atom and the phenyl ring, respectively. Fig. (8) illustrates a computer model of the ABA molecule, where the highly polar region (dark grey grid) and hydrophobic region (light grey grid) are accentuated. 


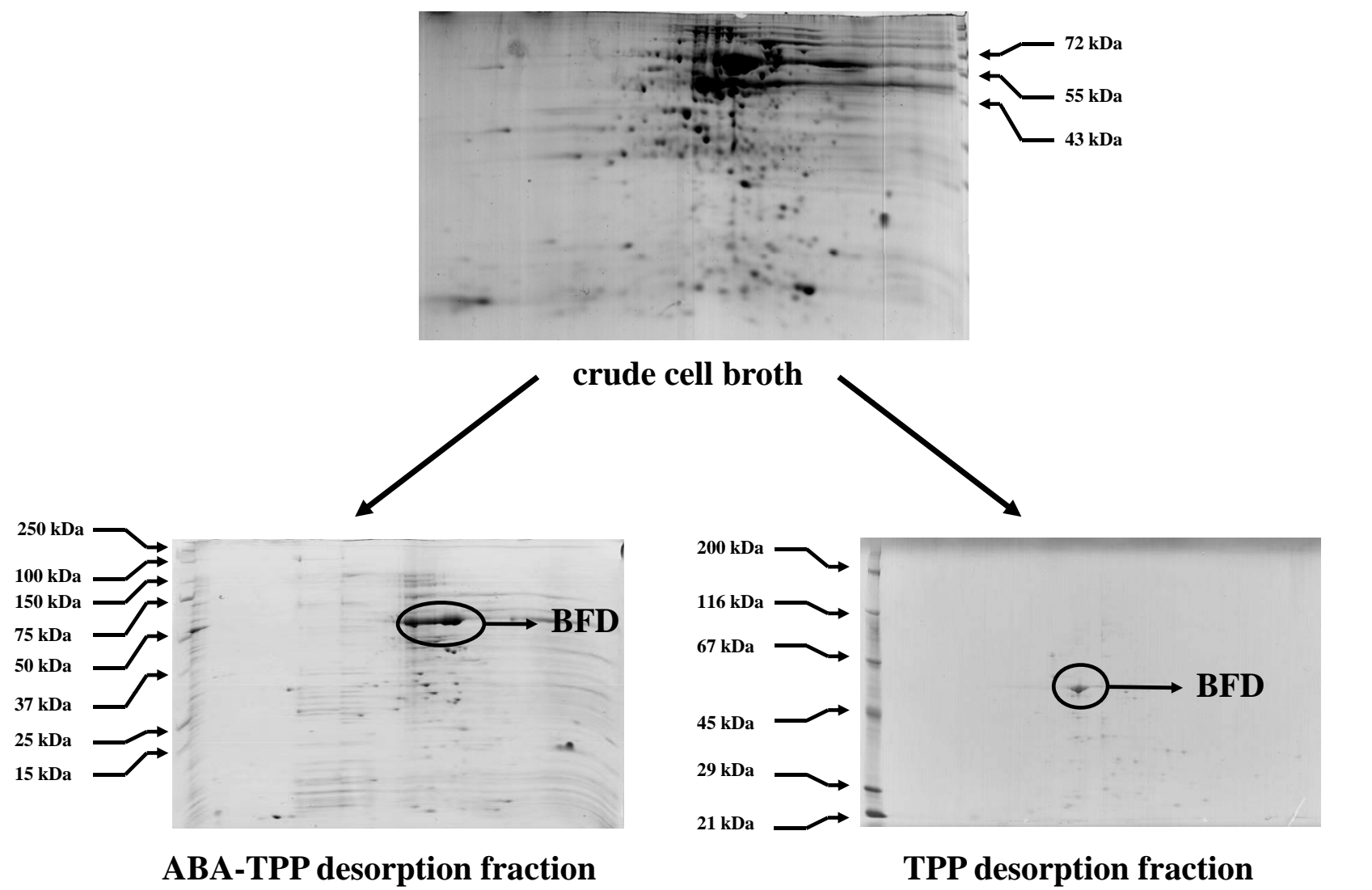

Fig. (6). top: the crude cell broth $(8-16 \%$ tris-HCL gel), left: ABA-TPP desorption fraction ( $8-16 \%$ tris-HCL gel), right: TPP desorption fraction (10\% tris-HCl gel).
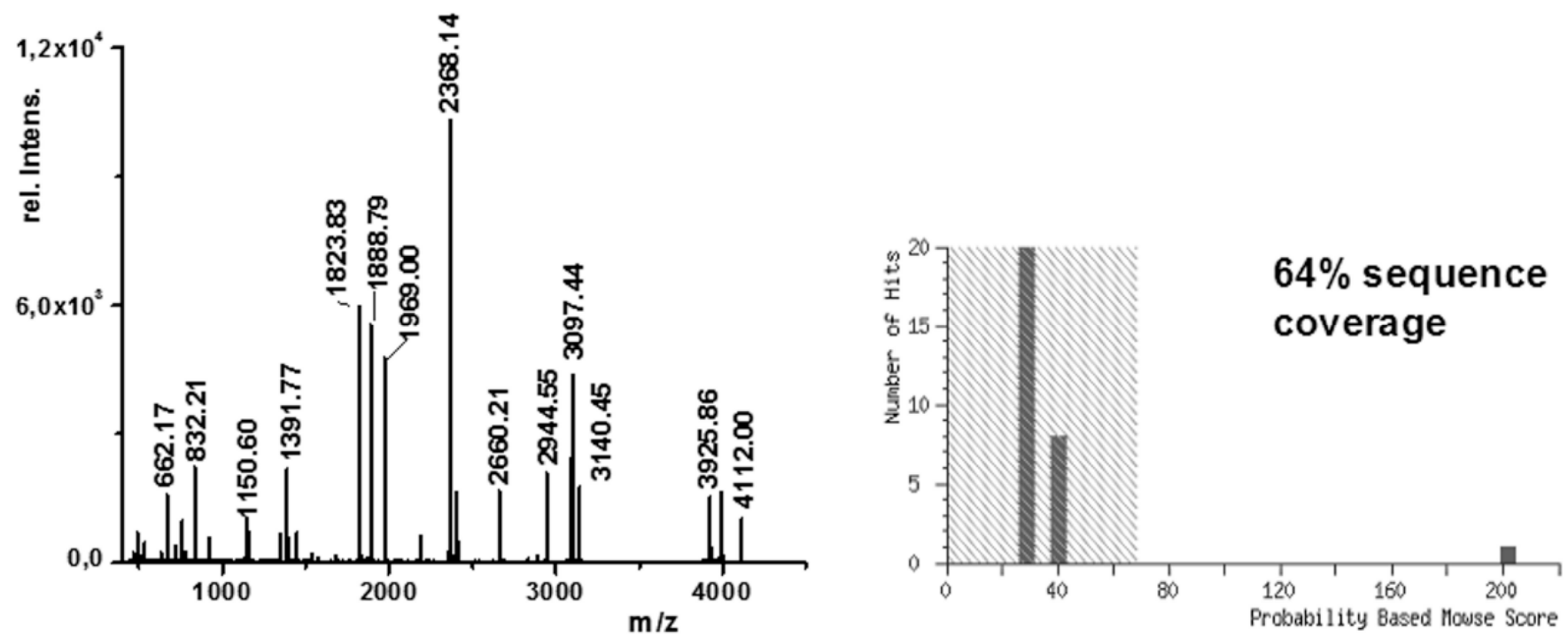

Fig. (7). Identification of BFD in 2DE for retracing the BFD during the separation process. Gel spots were excised and digested with trypsin. The peptides were spotted on a MALDI target. The peptide mass fingerprint of BFD is presented on the left and the subsequent Mascot search (right) provides positively identification of BFD with $64 \%$ sequence conformity.

The fraction collected with affinity separation without ABA is presented in Fig. (8) on the right hand side. The purification performance has improved and the specific enzyme activity in this desorption fraction is $41 \mathrm{U} / \mathrm{mg}$. The purification improves about the factor 4 , when $\mathrm{ABA}$ is absent. The ionic interactions can be suppressed by keeping the ionic strength high [33]. A sodium chloride concentration of $0.15 \mathrm{M}$ could be sufficient to prevent ionic interactions. However elevated ionic strength results in increase of hydrophobic interactions of the phenyl ring with aromatic 


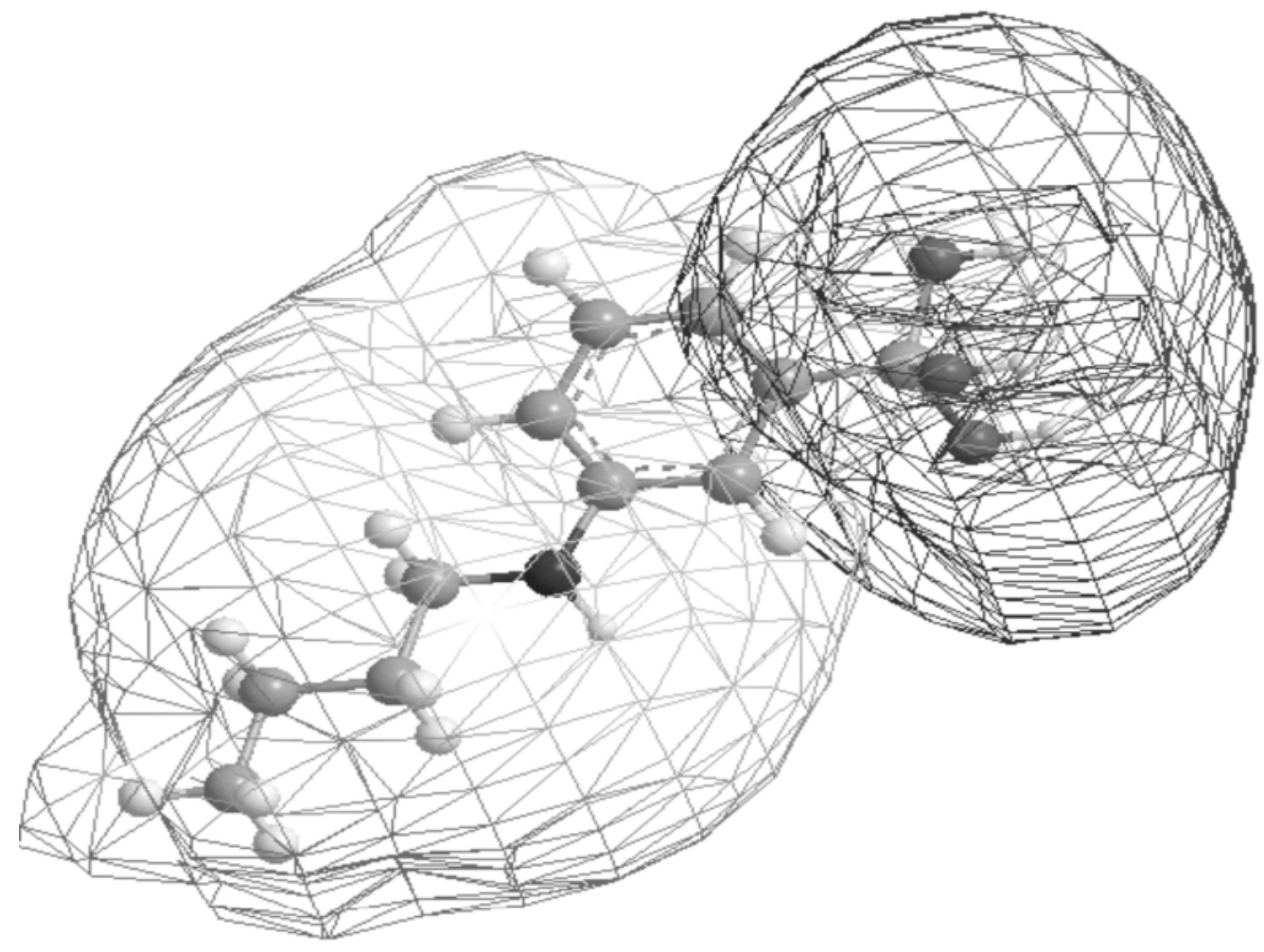

Fig. (8). Illustration of highly polar regions (dark grey grid) and hydrophobic regions (light grey grid) of ABA.

residues of proteins [11]. Singhal et al. emphasizes that the hydrophobic nature of the phenylboronates is the main hindrance for their application in biomacromolecule separation [10].

The use of diols enhances the success of using $\mathrm{ABA}$ for affinity separations of biomacromolecules like glycoproteins or RNA, because more ABA can be covered with the desired molecules. However publications dealing with glycoprotein isolation only applied synthetic mixtures of 2 to 4 proteins containing glycoproteins and non-glycoproteins [20, 34-36]. Exceptions are the work of Abraham et al. and Middle et al. applying ABA to natural mixtures. They used ABA for the determination of the ratio of glycated to non-glycated hemoglobin as a diagnostic tool for diabetes mellitus. However the dry mass of erythrocytes represents $95 \%$ of hemoglobin and a complete separation into glycated and non-glycated hemoglobin could not be achieved [37, 38]. Whenever a real sample was used a one-step purification of the desired proteins could not be reached [39]. The combination of lectins and ABA was also proposed [40]. Lectins alone are suitable for affinity separation processes and provide also mild desorption conditions [41]. Questionable is whether the multi-site attachment is favorable for the glycoprotein isolation.

\section{CONCLUSION}

The advantages of ABA are use of easy adsorption and desorption conditions by a simple $\mathrm{pH}$ shift, which conserves the function of the biomolecule. However the advantages do not compensate the main disadvantage, which is a low purification factor resulting from a low adsorption capacity of TPP and high nonspecific adsorption caused by a positive charge at the boron atom and a phenyl ring for hydrophobic interactions. In comparison the direct immobilization of the affinity ligand TPP is a better alternative represented by purification factor of 4 .

\section{ACKNOWLEDGEMENTS}

We would like to thank the working group of Prof. Liese from the Institute of Technical Biocatalysis, University of Technology (Hamburg, Germany) for handing over of the $E$. coli cells.

\section{REFERENCES}

[1] Hasson, M.S.; Muscate, A.; Henehan, G.T.M.; Guidinger, P.F.; Petsko, G.A.; Ringe, D.; Kenyon, G.L. Purification and crystallization of benzoylformate decarboxylase. Protein Sci., 1995, 4(5), 955-959.

[2] Hasson, M.S.; Muscate, A.; McLeish, M.J.; Polovnikova, L.S.; Gerlt, J.A.; Kenyon, G.L.; Petsko, G.A.; Ringe, D. The crystal structure of benzoylformate decarboxylase at 1.6 angstrom resolution: diversity of catalytic residues in thiamin diphosphatedependent enzymes. Biochemistry, 1998, 37(28), 9918-9930.

[3] Siegert, P.; McLeish, M.J.; Baumann, M.; Iding, H.; Kneen, M.M.; Kenyon, G.L.; Pohl, M. Exchanging the substrate specificities of pyruvate decarboxylase from Zymomonas mobilis and benzoylformate decarboxylase from Pseudomonas putida. Protein Eng. Des. Sel., 2005, 18(7), 345-357.

[4] Wilcocks, R.; Ward, O.P.; Collins, S.; Dewdney, N.J.; Hong, Y.P.; Prosen, E. Acyloin formation by benzoylformate decarboxylase from Pseudomonas Putida. Appl. Environ. Microbiol., 1992, 58(5), 1699-1704.

[5] Wilcocks, R.; Ward, O.P. Factors affecting 2hydroxypropiophenone formation by benzoylformate decarboxylase from Pseudomonas Putida. Biotechnol. Bioeng., 1992, 39(10), 1058-1063.

[6] Weiss, P.M.; Garcia, G.A.; Kenyon, G.L.; Cleland, W.W.; Cook, P.F. Kinetics and mechanism of benzoylformate decarboxylase using $\mathrm{C}-13$ and solvent deuterium-isotope effects on benzoylformate and benzoylformate analogs. Biochemistry, 1988, 27(6), 2197-2205. 
[7] Iding, H.; Dunnwald, T.; Greiner, L.; Liese, A.; Muller, M.; Siegert, P.; Grotzinger, J.; Demir, A.S.; Pohl, M. Benzoylformate decarboxylase from Pseudomonas putida as stable catalyst for the synthesis of chiral 2-hydroxy ketones. Chem.-Eur. J., 2000, 6(8), 1483-1495.

[8] Gala, D.; DiBenedetto, D.J.; Clark, J.E.; Murphy, B.L.; Schumacher, D.P.; Steinman, M. Preparations of antifungal Sch 42427/SM 9164: Preparative chromatographic resolution, and total asymmetric synthesis via enzymatic preparation of chiral alphahydroxy arylketones. Tetrahedron Lett., 1996, 37(5), 611-614.

[9] Schowen, R.L.; Kuebrich, J.P.; Wang, M.S.; Lupes, M.E. Mechanism of benzoin condensation. J. Am. Chem. Soc., 1971, 93(5), 1214-1220.

[10] Singhal, R.P.; Desilva, S.S.M. Boronate affinity-chromatography. Adv. Chromatogr., 1992, 31, 293-335.

[11] Liu, X.C. Boronic acids as ligands for affinity chromatography. Chinese J. Chromatogr., 2006, 24(1), 73-80.

[12] James, T.D. In Boronic Acids, Hall, D.G., Ed.; Wiley-VCH: Weinheim, 2005; pp. 441-479

[13] Bosch, L.I.; Fyles, T.M.; James, T.D. Binary and ternary phenylboronic acid complexes with saccharides and Lewis bases. Tetrahedron, 2004, 60(49), 11175-11190.

[14] Maestas, R.R.; Prieto, J.R.; Kuehn, G.D.; Hageman, J.H. Polyacrylamide-Boronate beads saturated with biomolecules - new general support for affinity-chromatography of enzymes. $J$. Chromatogr. A, 1980, 189(2), 225-231.

[15] Bouriotis, V.; Galpin, I.J.; Dean, P.D.G. Applications of immobilized phenylboronic acids as supports for group-specific ligands in the affinity-chromatography of enzymes. J. Chromatogr. $A, \mathbf{1 9 8 1}, 210(2), 267-278$.

[16] Bradford, M.M. A rapid and sensitive method for the quantitation of microgram quantities of protein utilizing the principle of proteindye binding. Anal. Biochem., 1976, 72, 248-254.

[17] Lopez-de-Alba, P.L.; Lopez-Martinez, L.; Cerda, V.; madorHernandez, J. Simultaneous determination and classification of riboflavin, thiamine, nicotinamide and pyridoxine in pharmaceutical formulations, by UV-visible spectrophotometry and multivariate analysis. J. Brazil. Chem. Soc., 2006, 17(4), 715-722.

[18] Rosenfeld, H.; Aniulyte, J.; Helmholz, H.; Liesiene, J.; Thiesen, P.; Niemeyer, B.; Prange, A. Comparison of modified supports on the base of glycoprotein interaction studies and of adsorption investigations. J. Chromatogr. A, 2005, 1092(1), 76-88.

[19] Wen, Z.Z.; Niemeyer, B. Evaluation of two different Concanavalin A affinity adsorbents for the adsorption of glucose oxidase. $J$. Chromatogr. B, 2007, 857(1), 149-157.

[20] Li, Y.; Pfuller, U.; Larsson, E.L.; Jungvid, H.; Galaev, I.Y.; Mattiasson, B. Separation of mistletoe lectins based on the degree of glycosylation using boronate affinity chromatography. $J$. Chromatogr. A, 2001, 925(1-2), 115-121.

[21] Matsuura, A.; Iwashima, A.; Nose, Y. Purification of thiaminebinding protein from Escherichia coli by affinity chromatography. Biochem. Biophys. Res. Commun., 1973, 51(1), 241-246.

[22] Muniyappa, K.; Adiga, P.R. Isolation and characterization of thiamin-binding protein from chicken egg white. Biochem. J., 1979, 177(3), 887-894.

[23] Springsteen, G.; Wang, B.H. A detailed examination of boronic acid-diol complexation. Tetrahedron, 2002, 58(26), 5291-5300.
[24] Lu, J.; Frank, E.L. Rapid HPLC measurement of thiamine and its phosphate esters in whole blood. Clin. Chem., 2008, 54(5), 901906.

[25] O'Brien, T.A.; Schrock, H.L.; Russell, P.; Blake, R.; Gennis, R.B. Preparation of Escherichia coli pyruvate oxidase utilizing a thiamine pyrophosphate affinity column. Biochim. Biophys. ActaEnzymol., 1976, 452(1), 13-29.

[26] Zopf, D.; Ohlson, S. Weak-affinity chromatography. Nature, 1990 , 346(6279), 87-88.

[27] Itokawa, Y.; Kimura, M.; Nishino, K. Thiamin-binding proteins. Ann. NY Acad. Sci., 1982, 378, 327-336.

[28] Muniyappa, K.; Adiga, P.R. Nature of the thiamin-binding protein from chicken egg yolk. Biochem. J., 1981, 193(3), 679-685.

[29] Griffith, T.W.; Leach, F.R. Effect of osmotic shock on vitamin transport in Escherichia coli. Arch. Biochem. Biophys., 1973, 159(2), 658-663.

[30] Nishimune, T.; Hayashi, R. Thiamine-binding protein and thiamine uptake by Escherichia coli. Biochim. Biophys. Acta-Gen. Subj., 1971, 244(3), 573-583

[31] Nishimura, H.; Uehara, Y.; Sempuku, K.; Iwashima, A. Purification and some properties of thiamine-binding protein from rice bran. J. Nutr. Sci. Vitaminol., 1984, 30(1), 1-10.

[32] Mitsunaga, T.; Matsuda, M.; Shimizu, M.; Iwashima, A. Isolation and properties of a thiamine-binding protein from buckwheat seed Cereal Chem., 1986, 63(4), 332-335.

[33] Lowe, C.R.; Dean, P.D. Affinity chromatography; John Wiley \& Sons: London, 1974.

[34] Ackerman, S.; Cool, B.; Furth, J.J. Removal of DNA from RNA by chromatography on acetylated n-[n'-(meta-dihydroxylborylphenyl) succinamyl]aminoethyl cellulose. Anal. Biochem., 1979, 100(1), 174-178

[35] Senel, S. Boronic acid carrying (2-hydroxyethylmethacrylate)based membranes for isolation of RNA. Colloid. Surf. APhysicochem. Eng. Asp., 2003, 219(1-3), 17-23.

[36] Preinerstorfer, B.; Lammerhofer, M.; Lindner, W. Synthesis and application of novel phenylboronate affinity materials based on organic polymer particles for selective trapping of glycoproteins. $J$. Sep. Sci., 2009, 32(10), 1673-1685.

[37] Abraham, E.C.; Perry, R.E.; Stallings, M. Application of affinitychromatography for separation and quantitation of glycosylated hemoglobins. J. Lab. Clin. Med., 1983, 102(2), 187-197.

[38] Middle, F.A.; Bannister, A.; Bellingham, A.J.; Dean, P.D.G. Separation of glycosylated hemoglobins using immobilized phenylboronic acid - effect of ligand concentration, column operating-conditions, and comparison with ion-exchange and isoelectric-focusing. Biochem. J., 1983, 209(3), 771-779.

[39] Brena, B.M.; Batistaviera, F.; Ryden, L.; Porath, J. selective adsorption of immunoglobulins and glucosylated proteins on phenylboronate agarose. J. Chromatogr. A., 1992, 604(1), 109-115.

[40] Monzo, A.; Bonn, G.K.; Guttman, A. Boronic acid-lectin affinity chromatography. 1. Simultaneous glycoprotein binding with selective or combined elution. Anal. Bioanal. Chem., 2007, 389(78), 2097-2102.

[41] Monzo, A.; Bonn, G.K.; Guttmann, A. Lectin-immobilization strategies for affinity purification and separation of glycoproteins. Trac-Trends Anal. Chem., 2007, 26(5), 423-432.

(C) Koetke et al.; Licensee Bentham Open.

This is an open access article licensed under the terms of the Creative Commons Attribution Non-Commercial License (http://creativecommons.org/licenses/by-nc/ 3.0/) which permits unrestricted, non-commercial use, distribution and reproduction in any medium, provided the work is properly cited. 